\title{
Vajinal doğum ve sezeryan öncesi ve sonrasında hastaların ağrı algılarına etki eden faktörlerin değerlendirilmesi
}

\section{Evaluation of the factors affecting pain perception of the patients before and after vaginal and cesarean delivery}

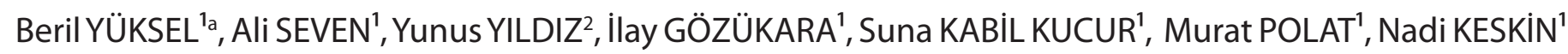

'Dumlupınar Üniversitesi Tıp Fakültesi Kadın Hastalıkları ve Doğum Anabilim Dalı, Kütahya,

${ }^{2}$ Dr. Vefa Tanır Ilgın Devlet Hastanesi Kadın Hastalıkları ve Doğum Kliniği, Konya, TÜRKiYE

\section{ÖZET}

Amaç: Bu çalışmanın amacı, doğum öncesi ve doğum sonrası, vizüel analog skala (VAS) skorlarının değerlendirilmesi ile sezaryen ve normal doğum yapan hastalarda ağrı algısına etki eden faktörlerin araştııılmasıdır.

Gereç ve Yöntemler: Dumlupınar Üniversitesi Tıp Fakültesi Kadın Hastalıkları ve Doğum Kliniğinde Ocak-Mart 2015 tarihleri arasında toplam 50 sezaryen ile doğum yapmış ve 50 normal doğum yapmış hasta çalışmaya alındı. Doğum öncesi ve sonrası VAS skorları değerlendirildi ve hastaların demografik özellikleri göz önüne alınarak veriler grup içi karşılaştııılı.

Bulgular: Normal doğum grubunda doğum öncesi ve sonrası VAS değerleri ortalaması sırasıyla 7,8 $\pm 2,2$ ve 7,2 $\pm 2,4$ olarak saptandı $(P>0,05)$. Gebelikteki izlem sayısı ile doğum sonrası VAS değerleri arasında negatif ilgileşim olduğu görüldü ( $P$ $=0,007$ ve $r=-0,37)$. Sezaryen grubunda doğum öncesi ve sonrası VAS ortalamaları sırasıyla $6,4 \pm 2,0$ ve $5,3 \pm 2,6$ olarak saptandı $(P=0,03)$. Vajinal doğumdan farklı olarak izlem sayısı VAS skorları arasında ilişki olmadığı saptandı $(P>0,05)$. Her iki grupta gelir düzeyinin, eğitim durumunun, izlem yerinin, epizyotomi açılmış olmasının veya eylem indüksiyon uygulanmasının doğum öncesi ve sonrası VAS değerlerine etki etmediği izlendi $(P>0,05)$.

Sonuçlar: Gebelik süresince doğumla ilgili eğitim ve psikolojik destek vermek hastanın doğum ve ağrısına dair endişesini azaltarak, doğum esnasında daha az ağı hissetmesini sağlayabilir. Denetimli gebelik okullarında verilecek eğitim, hastanın vajinal doğuma yönelmesini sağlayarak, hasta isteğine bağlı olan sezaryen sayılarının düşmesi ve sezaryen oranlarının azalmasına yardımcı olabilir.

Anahtar kelimeler: Gebelik, Ağrı, Doğum ağrısı

Sorumlu Yazara: Dr. Beril YÜKSEL, Dumlupınar Üniversitesi Tıp Fakültesi Kadın Hastalıkları ve Doğum Anabilim Dalı, 


\section{ABSTRACT}

Aim: The aim of this study is to evaluate the factors affecting pain perception of the patients, before and after vaginal and cesarean delivery by using visual analogue scale (VAS).

Material and Methods: The study enrolled 50 vaginal and 50 cesarean delivered patients applied to Dumlupinar University Obstetrics and Gynecology Clinic between January and March 2015. VAS scores were evaluated and variables were compared via demographic features within groups before and after delivery.

Results: In vaginal delivery group, before and after delivery VAS scores were $7.8 \pm 2.2$ and $7.2 \pm 2.4$ respectively $(\mathrm{P}>0.05)$. Negative correlation was determined between number of follow-up during pregnancy and after delivery VAS scores $(\mathrm{P}=$ 0.007 and $r=-0.37)$. In cesarean group, before and after delivery VAS scores were $6.4 \pm 2.0$ and $5.3 \pm 2.6$ respectively $(P=$ 0.03). Unlike vaginal delivery, no correlation was determined between number of follow-up during pregnancy and VAS scores ( $P>0.05$ ). Income level, educational status, follow-up center, episiotomy or implementation of labor induction had no effect on VAS scores before and after delivery $(P>0.05)$ in both groups.

Conclusion: Providing psychological support and childbirth education during pregnancy, can reduce the anxiety about the delivery, and can cause less pain perception during the delivery. Childbirth education given by supervised centers, will help to reduce the cesarean section rates due to patient request.

Key words: Pregnancy, Pain, Labor

\section{Giriş}

Doğum ağrısı, bir kadının hayatı boyunca hissettiği en ciddi ağrı olarak bildirilmiştir[1]. Gerek vajinal doğum gerekse sezaryen sonrası hissedilen ağrı ve analjezik ihtiyacını etkileyebilen birçok fizyolojik, psikolojik ve demografik faktörün olduğu gösterilmiştir [2]. Vajinal doğumdaki fiziksel ve demografik faktörler arasında genç yaş [1,3], dismenore öyküsü $[2,4]$, doğum indüksiyonu [5], hamilelik öncesi yüksek vücut kitle indeksi (VKI) [3], fetal makrozomi [1,6], fetal prezantasyon [7], distosi [8], nulliparite [3,6] gibi faktörlerin olduğu, yapılan çalışmalarda gösterilmiştir. Vajinal doğum gibi sezaryen sonrası postoperatif ağrı ve analjezik ihtiyacını etkileyen birçok psikolojik faktörün de olduğu gösterilmiştir $[9,10]$.

Doğum kadınların hayatındaki en ağrılı deneyim olarak ele alınabilir. Doğum ağrısı fizyolojik, psikososyal, kültürel ve çevresel faktörlerin etkileşimini içeren sübjektif bir deneyimdir. Fizyolojik faktörler doğum kanalına ait dokulara olan baskı ve dokuların gerilmesi ile ilgilidir. Psikososyal faktörler ise doğum sürecindeki korku, anksiyete ve onlarla baş etme yeteneği ile ilgilidir. Ayrıca kültürel değerler ve öğrenilmiş davranışlar da ağrıyı algılamayı ve ağrıya verilen cevabı etkilemektedir [2,11-16].

Ağrı şiddetinin değerlendirilmesinde standart olarak vizüel analog skala (VAS) veya sayısal ağrı ölçeği (NRS) yöntemleri kullanılır. Preoperatif, postoperatif veya doğum öncesi ve sonrası gibi kısa ve belirli dönemlerdeki ağrı şiddetinin değerlendirilmesinde bu yöntemler yüksek derecede efektif kabul edilmektedirler $[17,18]$. Bununla birlikte, her an ağrının şiddetinin kişi tarafından değişik algılanması, bir dakika öncesine göre kişinin ağrı algısının değişiklik göstermesi ve kişi ile skalayı uygulayan arasında etkileşimin gerekliliği nedeni ile bu skalaların kullanımı zorluk göstermektedir.
Kadın hastalıkları ve doğum hekimlerinin amacı anne adaylarının doğum sürecinde veya sonrasındaki ağrı süreçlerini olabildiğince azaltmak ve doğum tecrübesini anne adayları için daha keyifli bir hale getirmektir. Doğum ağrısına etki eden doğum öncesi faktörleri daha iyi anlamamız, doğum esnasındaki ağrı yönetimini daha iyi ve daha etkin yaparak kadınların doğum tecrübesini daha iyi hale getirecektir.

Bu çalışmanın amacı, hastanemizde vajinal yol ve sezaryen ile doğum yapan hastalarda, doğum öncesinde tahmin edilen ağrı ile doğum sonrasında hissedilen ağrı seviyelerini belirleyip, ağrı algılarına etki eden fiziksel ve demografik faktörlerin araştırılmasıdır.

\section{Gereç ve Yöntemler}

Dumlupınar Üniversitesi Tıp Fakültesi Kadın Hastalıkları ve Doğum Kliniğinde Şubat - Mart 2015 tarihleri arasında toplam 50 sezaryen ile doğum yapmış ve 50 normal doğum yapmış hasta çalışmaya dahil edildi. Örneklem büyüklüğünü tespit etmek için daha önce var olan literatür verileri baz alındı $[19,20]$. Yüksek riskli gebelikler, sistemik hastalı̆ı̆ veya çoğul gebeliği olan hastalar çalışmaya dahil edilmedi. Vajinal doğum yapan hastalara herhangi bir anestezi şekli uygulanmazken, sezeryan olan hastalardan sadece genel anestezi alanlar çalışmaya dahil edildi. Etik kurul onayı (Afyonkarahisar Klinik Araştırmalar Etik Kurulu, 19.02.2015, 2015/03, karar 96) alındıktan sonra hastalara çalışma hakkında bilgi verilerek onam formu imzalatıldı. Çalışmamıza katılan hastaların eğitim seviyeleri, aylık gelir düzeyleri, gebeliklerindeki izlem sayıları, izlemin nerede yapıldığı, doğum öncesinde gebelik okuluna gelip gelmedikleri, travayda kalış süreleri, indüksiyon alıp almadıkları ve epizyotomi varlığına dair veriler kaydedildi. Doğumun henüz latent fazında iken, vajinal doğum yapan 
hastalardan ( $n=50$ ), doğum esnasındaki ağrının ne kadar olabileceğini tahmin etmeleri ve vizüel analog skorlama (VAS) yöntemi ile 1 - 10 arasında bir sayıyı (1; en az - 10; en fazla) işaretlemeleri istendi. Postpartum birinci günde aynı hastalardan doğum esnasında hissedilen ağrıyı aynı şekilde 1 10 arasında bir sayı ile ifade etmeleri istendi. Elde edilen veriler birbirleri ile karşılaştırılarak ağrı şiddetine etki eden faktörler ayrıca değerlendirildi.

Sezaryen ile doğum yapan hastaların da $(n=50)$ aynı şekilde eğitim seviyeleri, aylık gelir düzeyleri, gebeliklerindeki izlem sayıları, izlemin nerede yapıldığı, doğum öncesinde gebelik okuluna gelip gelmedikleri kaydedildi. Bu hastalara da sezaryenden önce, postoperatif ağrılarının ne kadar olabileceği konusunda tahminde bulunmaları istendi. Aynı hastalara postoperatif birinci gündeki ağrı düzeyleri soruldu. Cevaplarını benzer şekilde VAS yöntemi ile ifade etmeleri istendi. Bu hastaların sezaryen sayısı ve postoperatif analjezik ihtiyacı da kaydedildi. Postoperatif analjezik miktarını standardize etmek için her hastaya ağrı durumunda 20 mg Tramadol (Contramal, Abdi İbrahim İlaç San. ve Tic. A.Ş., İstanbul) ampül uygulandı.

İstatistiksel analiz için SPSS, versiyon 19.0 (SPSS, Chicago, IL) kullanıldı. Verilerin dağılımı Kolmogorov-Smirnov testi ile araştırıldı. Normal dağılıma uyan verilerin karşılaştırılmasında, bağımlı verilerde paired sample t-test, korelasyon analizinde ise Pearson's correlation coefficient kullanıldı. Nominal verilerin karşılaştırılmasında Chi-Square test kullanıldı. P değeri 0.05 'ten küçük ise sonuç istatistiksel olarak anlamlı kabul edildi.

\section{Bulgular}

Hastaların eğitim düzeylerine bakıldığında vajinal doğum yapan grupta ilkokul mezunu 22 kişi (\%44), ortaokul mezunu 15 kişi (\%30), lise mezunu 10 kişi (\%20) ve üniversite mezunu 3 kişi (\%6) olduğu görüldü. Sezaryen grubunda ise ilkokul mezunu 17 kişi (\%34), ortaokul mezunu 16 kişi (\%32), lise mezunu 13 kişi (\%26) üniversite mezunu 4 kişi (\%8) mevcuttu. Gelir düzeylerine bakıldığında ise vajinal doğum grubunda aylık geliri 1500 TL altı olan 39 kişi (\%78) mevcutken, 1500 4000 TL arası 11 kişi (\%22) olduğu; 4000 TL üzeri kazancı olan hasta olmadığı görüldü. Sezaryen grubunda ise $1500 \mathrm{TL}$ altı 34 kişi (\%68), 1500 - 4000TL arası 15 kişi (\%30), 4000 - 10.000 TL arası 1 kişi (\%2) bulunmaktaydı. Sezaryen grubundaki hastalarımızın 27 tanesi (\%54) ilk kez sezaryen olurken, diğerlerinin iki veya üçüncü sezaryenleri idi. Vajinal doğum yapan grupta 4 kişinin (\%8), sezaryen grubunda ise sadece 1 kişinin gebelik okuluna geldiği görüldü. Grupların ortalama prenatal izlem sayıları normal vajinal doğum grubunda 12,1 \pm

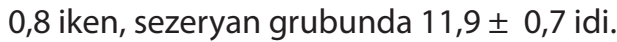

Normal doğum yapan hastalar kendi içlerinde değerlendirildiğinde, doğum öncesi (DÖ) ve doğum sonrası (DS) VAS değerleri ortalaması sırasıyla 7,8 $\pm 2,2$ ve 7,2 $\pm 2,4$ olarak saptandı $(P>0,05)$ (Tablo 1$)$. Hastaların gelir düzeyinin, eğitim durumunun, izlem yerinin, epizyotomi açılmış olmasının veya eylem indüksiyon uygulanmasının ağrı algısı açısından DÖ ve DS VAS değerlerine etki etmediği izlendi $(P>0,05)$ (Tablo 2). Gebelikteki izlem sayısı ile DS VAS değerleri arasında negatif korelasyon olduğu görüldü ( $P=0,007$ ve $r=-0,37)$.

Tablo 1. Normal doğum ve sezaryen doğum gruplarında doğum öncesi ve sonrası vizüel analog skala skorlarının karşılaştırılması.

\begin{tabular}{|l|c|c|c|}
\hline & DÖ VAS & DS VAS & P \\
\hline Normal doğum & $7,8 \pm 2,2$ & $7,2 \pm 2,4$ & 0.300 \\
\hline Sezaryen doğum & $6,4 \pm 2,0$ & $5,3 \pm 2,6$ & 0.03 \\
\hline
\end{tabular}

Paired sample t-test kullanıldı. Veriler ortalama \pm St. Deviasyon olarak verildi.

$\mathrm{P}<0,05$ ise anlamlı olarak kabul edildi.

Kısaltmalar:DÖ; doğumöncesi, DS; doğum sonrası, VAS; vizüel analog skala.

Tablo 2. Normal doğum yapan hastalarda doğum öncesi ve sonrası vizüel analog skala skorlarının karşılaştırılması

\begin{tabular}{|l|c|c|c|}
\hline & DÖ VAS & DS VAS & P \\
\hline Eğitim Durumu & & & \\
İlkokul mezunu değil & $6,5 \pm 2,3$ & $6,8 \pm 1,8$ & \\
İlkokul & $6,9 \pm 2,1$ & $6,1 \pm 2,0$ & \\
Ortaokul & $6,2 \pm 2,0$ & $6,8 \pm 2,8$ & 0,100 \\
Lise & $6,8 \pm 1,9$ & $6,5 \pm 2,6$ & \\
Üniversite & $6,9 \pm 1,9$ & $6,5 \pm 1,8$ & \\
\hline Gelir düzeyi & & & \\
$<1500$ TL & $7,2 \pm 2,1$ & $6,9 \pm 2,3$ & \\
1500 - 4000TL arası & $6,9 \pm 2,3$ & $6,8 \pm 2,5$ & 0,400 \\
$>4000$ TL & $7 \pm 2,1$ & $6,7 \pm 2,3$ & \\
\hline İzlem yeri & & & \\
Aile Hekimi & $6,9 \pm 2,1$ & $6,8 \pm 2,8$ & \\
Devlet Hastanesi & $6,9 \pm 1,9$ & $6,8 \pm 2,8$ & 0,300 \\
Özel Kurum & $6,5 \pm 2,3$ & $6,8 \pm 2,8$ & \\
\hline Epizyotomi & & & \\
Var & $6,5 \pm 2,3$ & $6,1 \pm 2,0$ & 0,600 \\
Yok & $6,2 \pm 2,0$ & $6,5 \pm 1,8$ & \\
\hline Eylem indüksiyonu & & & \\
Var & $6,9 \pm 1,9$ & $6,7 \pm 2,3$ & 0,500 \\
Yok & $6,8 \pm 1,9$ & $6,9 \pm 2,1$ & \\
\hline
\end{tabular}

Paired sample t-test kullanıldı. Veriler ortalama \pm st. deviasyon olarak verildi.

$\mathrm{P}<0,05$ ise anlamlı olarak kabul edildi.

Kısaltmalar: DÖ; doğum öncesi, DS; doğum sonrası, VAS; vizüel analog skala.

Sezaryen olan hastalar kendi içlerinde değerlendirildiğinde ise pre-operatif ve post-operatif VAS ortalamaları sırasıyla $6,4 \pm 2,0$ ve $5,3 \pm 2,6$ olarak saptandı $(P=0,03$ ) (Tablo 1). Normal doğum grubunda olduğu gibi gelir düzeyinin, eğitim durumunun ve izlem yerinin pre ve postoperatif VAS değerleri üzerine bir etkisi olmadığı izlendi ( $>$ > 0,05) (Tablo 3). Vajinal doğumdan 
farklı olarak izlem sayısı VAS skorları arasında ilişki olmadığı saptandı $(P>0,05)$. Fakat istatistiksel olarak anlamlı olmasa da geçirilmiş sezaryen operasyonu bulunanların preoperatif VAS tahminlerinin, ilk kez sezaryen olacaklara göre daha yüksek olduğu ( $P=0,07$, postoperatif dönemde ise ilk kez sezaryen olanların, geçirilmiş sezaryenleri olan hastalara göre daha yüksek VAS değerlerine sahip olduğu izlendi $(P=0,2)$.

Tablo 3. Sezaryen doğum yapan hastalarda doğum öncesi ve sonrası vizüel analog skala skorlarının karşılaştırılması

\begin{tabular}{|l|c|l|l|}
\hline & DÖ VAS & DS VAS & P \\
\hline Eğitim Durumu & & & \\
İlkokul mezunu değil & $6,7 \pm 2,1$ & $6,8 \pm 1,8$ & \\
İlkokul & $6,5 \pm 2,1$ & $6,4 \pm 2,0$ & \\
Ortaokul & $6,9 \pm 2,5$ & $6,8 \pm 2,9$ & 0,600 \\
Lise & $7 \pm 1,9$ & $6,4 \pm 2,1$ & \\
Üniversite & $6,4 \pm 1,9$ & $6,7 \pm 1,4$ & \\
\hline Gelir düzeyi & & & \\
$<1500 T L$ & $6,1 \pm 2,1$ & $6,3 \pm 2,2$ & \\
1500 - 4000TL arası & $6,5 \pm 2,6$ & $6,2 \pm 2,1$ & 0,200 \\
$>$ 4000TL & $7,1 \pm 2,3$ & $6,9 \pm 2,3$ & \\
\hline İzlem yeri & & & \\
Aile Hekimi & $6,4 \pm 2,1$ & $6,6 \pm 2,2$ & \\
Devlet Hastanesi & $6,4 \pm 1,9$ & $6,5 \pm 2,2$ & 0,700 \\
Özel Kurum & $6,1 \pm 2,7$ & $6,8 \pm 2,5$ & \\
\hline
\end{tabular}

Paired sample t-test kullanıldı. Veriler ortalama \pm st. deviasyon olarak verildi.

$\mathrm{P}<0,05$ ise anlamlı olarak kabul edildi.

Kısaltmalar:DÖ; doğum öncesi, DS; doğum sonrası, VAS; vizüel analog skala Sezaryen grubu ile vajinal doğum yapan hasta grubu karşılaştırıldığında ise hem DÖ, hem DS için VAS değerlerinin sezaryen grubunda anlamlı olarak daha düşük olduğu görüldü $(P=0,002$ ve $P=0,000)$.

Gebe okuluna giden hasta sayılarına bakıldığında, normal doğum yapan hastaların sadece 4'ünün sezaryen yapılan hastaların ise sadece birinin okula başvurduğu görüldü. Sezaryen grubunda narkotik analjezik ihtiyacının pre-operatif VAS değeri daha yüksek olan hastalarda, düşük olan hastalara göre daha fazla olmakla beraber sonucun istatistiksel olarak anlamlı olmadığı görüldü $(P=0,12)$.

\section{Tartışma}

İnsanlık tarihi boyunca toplumun odak unsuru olan kadınlar, dünya nüfusunun yarısını oluşturmakta, doğurganlık özellikleri ile insanoğlunun devamlılığını sağlamakta ve toplum yapısının devamlıı̆ıının garantisi olarak sosyal yapıya önemli katkıda bulunmaktadır. Doğum kadın için hayatı boyunca birçok kez deneyim edebileceği bir olgu olup, fizyolojik bir süreç olmasına rağmen anneyi bedensel ve ruhsal olarak etkileyebilmektedir. Doğum sürecinin kadın sağlığını olumsuz etkilemeden devam etmesinde ve sonuçlanmasında birçok etken rol oynamaktadır [21,23].

Yapılan bir çalışmada, annelerden doğum deneyimini değerlendirmeleri istenmiş ve buna göre, \%47,3'ü doğumunu "çok kolay", \%31,3'ü "sıkıntılı" olarak belirtmiştir [23]. Bir başka çalışmada ise annelerin yarıdan fazlası (\%57) doğum deneyimini zor ve yorucu olarak tanımlamışlardır [24].

Bizim çalışmamızda sonuçlar incelendiğinde, hastaların sezaryen ile daha az ağrı duyacaklarını tahmin ettikleri ve vajinal doğum esnasında hissedilen ağrı düzeyi için daha yüksek değerler işaretledikleri saptanmıştır. Ekolarak, bireylerin gelir düzeyinin, eğitim durumunun, izlem yerinin, epizyotomi açılmış olması veya eylem indüksiyonu uygulanması gibi faktörlerin hastaların ağrı beklentisine veya doğum sonrası hissettiklerini söyledikleri ağrı düzeyine herhangi bir etkisi olmadığı izlenmiştir. Yapılan bir çalışmada Türkiye'de elektif sezaryen isteyen hastaların tercihlerinin sebepleri araştırılmış ve \%45,2 ile en sık nedenin doğum korkusu olduğu gösterilmiştir [25]. Yine aynı çalışmada "doğum ağrısı korkusu" \%19 bulunmuştur. Bu sonuç, bizim çalışmamızda da ortaya çıkan; hastaların doğum öncesi beklentilerini ölçen VAS değerlerinin, sezaryen grubunda vajinal doğum grubuna göre daha düşük olması sonucu ile uyumlu görünmektedir. Yine ülkemizde gerçekleştirilen bir başka çalışmada primipar kadınların doğum tercihleri sorgulanmış; sezaryen ile doğum yapanların tercih nedenleri arasında \%71,1 oranla en fazla doğumdan ve doğum ağrısından korkma bulunmuştur [26]. Tüm bu sonuçlar, vajinal doğum korkusunun halen hastalarımız arasında ne kadar yaygın olduğunu gösterir niteliktedir. Sezeryan olan hastalardaki ağrı beklentisinin ve sonrasında hissedilen ağrının da sübjektif olarak vajinal doğuma göre daha az olmasının bu algı ile ilişkili olabileceği görülmektedir. Bunun önüne geçmenin en temel yolu, elbette hastaların gerek gebelik öncesinde gerekse gebelik dönemlerinde uygun eğitimi almaları ve sorularına karşılık bulabilecekleri uygun iletişim ortamlarının bulunabilmesi ile mümkün olacaktır. Bunun için belirli bir merkeze yönlendirme imkanı olmasa dahi, poliklinik vizitleri esnasında olabildiğince hastalara bu konuya yönelik olarak verilecek desteğin önemli olacağı kanaatindeyiz. Nitekim bizim sonuçlarımızda da vajinal doğum yapan hastaların doğum sonrasında belirtikleri ağrının prenatal vizit sayısı ile negatif korelasyon gösterdiği izlenmiştir. Vajinal doğum ve sezaryen gruplarının arasındaki doğum sonrası VAS skorlarının farklı olması; ağrılarının nitelikleri ve kaynağının farklı olması faktörünü ön plana çıkarmaktadır. Bu konunun önceki doğumunu vajinal doğum şeklinde yapan ve daha sonra sezaryen ile doğum yapan hastalarda çalışmalar yapılarak daha net ortaya konabileceğini düşünmekteyiz.

Bizim çalışmamızda ortaya çıktığı gibi, hastalarda görülen vajinal doğum ağrısının daha fazla olacağı öngörüsünün vajinal doğum yapacak hastalara daha iyi danışmalık hizmeti verilerek veya ağrısız doğum alternatifleri konusunda daha detaylı bilgilendirme yapılarak aşılabileceğini düşünmekteyiz. Bunun için hastaların, hastaneler içinde hizmet veren denetimli gebe okullarına yönlendirilmesinin faydalı olabileceğine inanmaktayız. Hastanemiz kliniğinde gebe okulu bulunmasına rağmen benzer hizmet, çalışmamızın öngörüsü ışığında kısmen poliklinik muayeneleri esnasında da hastalara 
sunulmaktadır. Fakat hastalarımıza bu eğitimlere gitmeleri konusunda bizzat yönlendirme noktasındaki eksiğimiz bizim özeleştirimiz olmuştur. Literatürde de doğum öncesi egzersiz sınıflarına katılan gebelerin doğum korkusunun egzersizlere katılmadan önceki hallerine göre daha az olduğu gösterilmiştir [27]. Nitekim bu çalışmaya paralel olarak, bizim sonuçlarımıza bakıldığında; en azından poliklinikte dahi olsa gebelikteki izlem sayıları arttıkça hastaların vajinal doğum esnasında hissettiklerini söyledikleri ağrı düzeyinde azalma olduğu görülmüştür. İleride gebe okullarının daha aktif hale gelmesiyle belirtilen değişikliklerin daha belirgin hale geleceğini düşünmekteyiz.

Sezaryen grubunda preoperatif VAS değeri daha fazla olan hastalarda narkotik analjezik ihtiyacının daha fazla olduğu saptanmasına rağmen bu bulgu istatistiksel açıdan anlamlı değildi. Bunun nedeni olarak, bu hastaların ağrı eşiğinin düşük olması nedeniyle postoperatif daha fazla ağrı hissedeceklerini düşünmeleri sebebiyle olabileceğini düşünmekteyiz.

Hem doğum, hem de doğum ağrısı olsun ikisi de kadının hayatında psikososyal açıdan en fazla iz bırakan tecrübelerdendir. Doğum ağrısının nedenlerinin daha iyi anlaşılması hastaların doğum başlamadan önce ağrı düzeylerinin tahmin edilmesine ve buna yönelik önlem ve uygulamaların yapılmasını sağlayacaktır. Hastalara gebelik süresince gerek poliklinikte, gerek denetimli gebelik okullarında doğumla ilgili eğitim ve psikolojik destek vermek hastanın doğum ve ağrısına dair endişesini azaltarak, doğum esnasında daha az ağrı hissetmesini sağlayabilir. Yine bu denetimli gebelik okullarında verilecek eğitim; hastanın sezaryen yerine vajinal doğuma yönelmesini sağlayarak, hasta isteğine bağlı olan sezaryen sayılarının düşmesi ve sezaryen oranlarının azalmasına yardımcı olabilir.

\section{Çıkar çatışması ve Finansman Beyanı}

Bu çalışmada çıkar çatışması ve finansman destek alındığı beyan edilmemiştir.

\section{Kaynaklar}

1. Melzack R, Kinch R, Dobkin P, Lebrun M, Taenzer P. Severity of labour pain: influence of physical as well as psychologic variables. Can Med Assoc J 1984; 130: 579-84.

2. Lowe NK. The nature of labor pain. Am J Obstet Gynecol 2002; 186: S16-24.

3. Melzack R, Taenzer P, Feldman P, Kinch RA. Labour is still painful after prepared childbirth training. Can Med Assoc J 1981; 125: 357-63.

4. Melzack R, Bélanger E. Labour pain: correlations with menstrual pain and acute low-back pain before and during pregnancy. Pain 1989; 36: 225-9.

5. Hildingsson I, Karlström A, Nystedt A. Women's experiences of induction of labour--findings from a Swedish regional study. Aust N Z J Obstet Gynaecol 2011; 51: 151-7.

6. Hess PE, Pratt SD, Lucas TP,et al. Predictors of breakthrough pain during labor epidural analgesia. Anesth Analg 2001; 93: 414-8

7. Benavides L, Wu JM, Hundley AF, Ivester TS, Visco AG. The impact of occiput posterior fetal head position on the risk of anal sphincter injury in forceps-assisted vaginal deliveries. Am J Obstet Gynecol 2005; 192: 1702-6.

8. Panni MK, Segal S. Local anesthetic requirements are greater in dystocia than in normal labor. Anesthesiology 2003; 98: 957-63.

9. Hinrichs-Rocker A, Schulz K, Järvinen I, Lefering R, Simanski C, Neugebauer EA. Psychosocial predictors and correlates for chronic postsurgical pain (CPSP) - a systematic review. Eur J Pain 2009; 13: 719-30.

10. Ip HY, Abrishami A, Peng PW, Wong J, Chung F. Predictors of postoperative pain and analgesic consumption: a qualitative systematic review. Anesthesiology 2009; 111: 657-77.

11. Caton D, Corry MP, Frigoletto FD, et al. The nature and management of labor pain: executive summary. Am J Obstet Gynecol 2002; 186: S1-15.

12. Hodnett ED. Pain and women's satisfaction with the experience of childbirth: a systematic review. Am J Obstet Gynecol 2002;186: S160-72.

13. Leeman L, Fontaine P, King V, Klein MC, Ratcliffe S. Management of labor pain: promoting patient choice. Am Fam Physician 2003; 68: 1023, 1026, 1033 passim.

14. Leeman L, Fontaine $P$, King V, Klein MC, Ratcliffe $S$. The nature and management of labor pain: part I. Nonpharmacologic pain relief. Am Fam Physician 2003; 68: 1109-12.

15. Leeman L, Fontaine $P$, King V, Klein MC, Ratcliffe $S$. The nature and management of labor pain: part II. Pharmacologic pain relief. Am Fam Physician 2003; 68: 1115-20.

16. Zwelling $\mathrm{E}$, Johnson $\mathrm{K}$, Allen J. How to implement complementary therapies for laboring women. MCN Am J Matern Child Nurs 2006;31: 364-70; quiz 371-2.

17. Jansen MP. Measurement of pain. In: Fishman SM, Ballantyne JC, Rahmell JP, eds. Bonica's management of pain, 4th edn. Media, Philedelphia: Lippencoth Williams \& Wilkins, 2010; 251-70.

18. Turk DC, Melzack R. Handbook of pain assessment. New York: The Guilford Press, 1992.

19. Ergöl Ş, Kürtüncü M. Bir üniversite hastanesinde kadınların sezeryan doğum tercihlerini etkileyen faktörler. Hacettepe Üniversitesi Hemşirelik Fakültesi Dergisi 2014; 26-34.

20. Duran E, Atan Ş, Kadınların sezeryan/vajinal doğuma ilişkin bakış açılarını kalitatif analizi. Genel Tıp Derg 2011; 21: 83-8.

21. Taskın L. Doğum ve Kadın Sağlığı Hemsireliği, Sistem Ofset Matbaacılık, Ankara, 2000; 85-8.

22. Lowdermilk DL, Pery SE, Bobok IM. Maternity Women's Health Care, Mosby, London, 2000; 55-8.

23. Pınar G, Doğan N, Algıer L, Kaya N, Cakmak F. Annelerin doğum sonu konforunu etkileyen faktörler. Factors that affecting mothers' postnatal comfort. Dicle Tıp Derg 2009; 36: 184-90.

24. CoskunG.DoğumSonuBakımınAnnelerTarafındanDeğerlendirilmesi. Mersin Üniversitesi SBE Yüksek Lisans Tezi, Mersin, 2003.

25. Buyukbayrak EE, Kaymaz O, Kars B, et al. Caesarean delivery or vaginal birth: preference of Turkish pregnant women and influencing factors. J Obstet Gynaecol 2010; 30: 155-8.

26. Gözükara F, Eroğlu K. İlk Doğumunu Yapmış Kadınların (Primipar) Doğum Şekline Yönelik Tercihlerini Etkileyen Faktörler Sağlık Bilimleri Fakültesi Hemşirelik Dergisi 2008; 32-46.

27. Guszkowska M. Exercise dependence-symptoms and mechanisms. Psychiatr Pol 2012; 46: 845-56. 